\title{
Behaviour of veal calves in individual crates and in group pens
}

J. G. de Wilt (Institute of Agricultural Engineering (IMAG), P.O. Box 43, 6700 AA Wageningen, Netherlands)

Received 21 March 1986; accepted 13 May 1986

Abstract. The behaviour of veal calves housed in individual crates or in groups of five and fed from open buckets was observed. The differences in behaviour of the calves in both housing systems were discussed in terms of animal welfare.

Key words: behaviour, welfare, veal calves, housing systems, group housing, individual housing.

Introduction. The individual housing of veal calves in crates has received prolonged and serious criticism since it imposes many behavioural restrictions to the animals. In the present study, a group housing system is introduced as a possible alternative, and the behaviour and welfare status of the calves in both housing systems is compared.

Material and methods. In four consecutive experiments a total of 48 calves were housed individually and 140 in groups of five. All animals were male $\mathrm{FH}$ (FriesianHolland) $\times$ HF (Holstein-Friesian) or MRY (Meuse-Rhine-Yssel) and kept in the calf-house from the age of about one week until slaughter at about 22 weeks of age. The crates $(1.70 \mathrm{~m} \times 0.70 \mathrm{~m})$ consisted of two solid sidewalls $(1.10 \mathrm{~m}$ high $)$, a partly opened front and back part and a wooden slatted floor. The group pens $(2.40 \mathrm{~m} \times$ $3.05 \mathrm{~m})$ were surrounded by galvanized fences $(1.10 \mathrm{~m}$ high) and a wall on the back side; the front part of the floor was made of wooden or concrete slats. During the first six weeks after arrival the group-housed calves were tethered to the feeding gate by neck chains $(0.35 \mathrm{~m}$ long) and separated individually by wooden partitions $(0.60 \mathrm{~m}$ long, $0.80 \mathrm{~m}$ high) which were removed when the calves were untethered. All calves were fed a milk replacer in open buckets twice daily around $08 \mathrm{~h} 00$ and $16 \mathrm{~h} 00$. In addition, each calf received $200 \mathrm{~g}$ of cobs of chopped straw daily from week 7 or 9 onwards. The behaviour of each calf was recorded by direct observation once every 10 minutes during 24 hours in weeks $8,12,16$ and 20 after arrival, feeding periods excepted.

Results. The incidence of the different lying postures is expressed as a percentage of total lying, whereas the occurrence of all other activities is calculated as a percentage of the total number of observations. The behavioural differences between calves in individual crates and those in group pens are analysed against variance within experiments. These differences are significant $(P \leqslant 0.01)$. 
The calves in the individual crates spent more time lying than those in the group pens ( $74 \%$ against $68 \%$ ) due to the greater variation of stimuli in the group pens and maybe also to the occasional mounting and treading of lying calves by penmates.

In the crates, lying on the side or on the brisket with both hindlegs stretched ( $20 \%$ and $8 \%$ respectively in the group pens) was restricted by the side-walls, and almost impossible at the end of the fattening period. These restrictions may interfere with the relaxation of the body and seemed to affect behavioural thermoregulation.

Lying with the head backwards, which is the usual posture for supporting the head (in the group pens $20-25 \%$ ), became increasingly restricted by the side-walls of the individual crates towards the end of the fattening period. The duration of this posture decreased in the crates from $25 \%$ in week 8 to $5 \%$ in week 20 . Although at the end of the fattening period the head was supported more often forwards on the floor $(10 \%$ instead of $5 \%)$ or against the partitions $(1-2 \%)$, the total duration of lying with the head supported was then clearly reduced in the crates in comparison to the group pens $(17 \%$ against $30 \%)$. The latter percentage includes lying with the head on pen-mates in the group pens $(5 \%)$. Since supporting the head is necessary for the relaxation of the neck muscles during certain states of sleep (Ruckebusch \& Bell, 1970), the restriction of these lying postures in the crates may interfere with sleep as a physiological process.

Furthermore, licking of the belly, back, thighs or hindlegs $(1.7 \%$ in the crates, $3.2 \%$ in the group pens) was hindered by the side-walls of the crates, whereas licking of the forelegs $(1.0 \%$ against $0.7 \%)$ and the muzzle $(1.9 \%$ against $1.1 \%)$, which are easily accessible, was more frequently performed by the crated calves than by the group-housed ones. The increase of the latter activities (displacement or redirected behaviours) may indicate conflict situations in the crates.

In the group pens licking occurred regularly throughout the day $(2.5 \%)$ and head butting and mounting were also performed (together $1.0 \%$ ). Intersucking, sucking at the prepuce of pen-mates and urine drinking were rare in this period from 8 to 20 weeks after arrival. The individually housed animals showed a need for social contacts by their regular reaching over the side-walls, their head butting against parts of the crate and their frequent jumping as an introduction to social play (Reinhardt, 1980).

Furthermore, as a consequence of the limited (visual) contact with the environment, the calves in the crates reacted to sudden noises by standing up immediately, in contrast to their congeners in the group pens, which could see their direct environment even when lying.

The duration of intake (1.2-1.5\%) and rumination (8.3-9.5\%) of the limited amount of straw cobs was comparable in crates and group pens. The performance of stereotypies such as licking (4-5\%) or scraping (2-3\%) of objects and tongue playing ( $2 \%$ ) was not affected by housing type, but these activities can be reduced by the provision of more (adequate) roughage (Graf, 1985).

Conclusions. The group housing of veal calves is an important step towards im- 
proved calf welfare, since it removes some serious behavioural restrictions which can occur in individual crates. This concerns the ability to ly on the side or on the brisket with both hindlegs stretched, to support the head during lying, to groom, to interact with congeners and to explore the direct surroundings. The frequency of stereotypies, which is partly dependent on the roughage provided, is not reduced in the group pens.

\section{References}

Graf, B., 1985. Verhaltensanomalien im Funktionskreis Fressverhalten bei intensiv gehaltenen Mastbullen. 4. GTF-Seminar 'Angewandte Nutztierethologie', Grub.

Reinhardt, V., 1980. Untersuchung zum Sozialverhalten des Rindes. In: Tierhaltung 10. Birkhäuser Verlag, Basel.

Ruckebusch, Y. \& F. R. Bell, 1970. Etude électropolygrafique et comportementale des états de veille et de sommeil chez la vache (Bos taurus). Annales de Recherches Vétérinaires 1: 41-62.

This synopsis is based on part of a doctoral thesis, Agricultural University, Wageningen, 1985, also published by the Institute of Agricultural Engineering (IMAG),Wageningen. 138 pp., 49 figs., 54 tables, 195 refs., 8 appendices.

Available as paper copy (order R055P, $f 30$ including postage) or microfiches (order R055M, $f 17.50$ including postage) at: NARD, clo Pudoc, P.O. Box 4, 6700 AA Wageningen, Netherlands (telex 45015 blhwg $\mathrm{nl}$ ). 